wide Survey. European Journal of Neurology. 2012; 19:163-167.

32. W.S. Cho, J.E. Kim, C.H. Kim et al. Oh. Long-term outcomes after combined revascularization surgery in adult moyamoya disease. Stroke. 2014; 45:3025-3031.

33. J. Karasawa, H. Kikuchi, S. Furuse et al. A surgical treatment of "moyamoya" disease "encephalo-myosynangiosis". Neurologia medico-chirurgica (Tokyo). 1977; 17:29-37.

34. K.C. Wang, J.H. Phi, J.Y. Lee et al. Indirect revascularization surgery for moyamoya disease in children and its special considerations. Korean Journal of Pediatrics. 2012; 55:408-413.

35. S.K. Kim, B.K. Cho, J.H. Phi et al. Pediatric moyamoya disease: An analysis of 410 consecutive cases. Annals of Neurology. 2010; 68:92-101.

Статья поступила в редакцию 10.11.2018

\section{Координаты для связи}

Данько Константин Леонидович, студент 6 курса ФГБОУ ВО Амурская ГМА Минздрава России.

Никитенко Павел Сергеевич, врач-невролог неврологического отделения для больных с острым нарушением мозгового кровообращения ГАУЗ AO «Благовещенская городская клиническая больница». E-mail: amurdoctor1690@gmail.com

Почтовый адрес ГАУЗ АО «Благовещенская городская клиническая больница»: 675000 г. Благовещенск, ул. Больничная, 32.

Заваруев Артем Владимирович, врач-хирург отделения сосудистой хирургии Амурской областной клинической больницы, ассистент кафедры госпитальной хирургии ФГБОУ ВО Амурская ГМА Минздрава России.

Почтовый адрес ФГБОУ ВО Амурская ГМА Минздрава России: 675000, г. Благовещенск, ул. Горького, 95.

E-mail: science.prorector@AmurSMA.su
УдК: 615.065:577.21

Е.А. Бородин

ФГБОУ ВО Амурская ГМА Минздрава России

г. Благовещенск

\section{ПЕРСОНИФИЦИРОВАННАЯ МЕДИЦИНА} И БИОИНФОРМАТИКА

Исторически сложились две философские концепции медицины. В основе первой, уходящей своими корнями в древние времена, лежит холистический взгляд на природу человека. Организм человека - единое целое, лечить нужно не болезнь, а больного (Гиппократ, М.Я. Мудров, Н.И. Пирогов, С.П. Боткин, восточная медицина). Вторая концепция, зародившаяся в XIX веке и доминирующая в современной медицине, требует всегда найти материальный субстрат болезни (Рудольф Вирхов, целлюлярная теория патологии). Бурный прогресс в области биологии в XX веке неузнаваемо изменил медицину. Причина болезни сегодня видится даже не повреждениях клеток, а в молекулярных дефектах, возникающих в результате нарушения генетического аппарата клетки (Лайнус Поллинг, концепция молекулярных болезней). Фактически предлагается лечить даже не болезнь, а дефекты молекул. Задача медицины видится в подборе лекарственных средств, способных устранить имеющийся молекулярный дефект (таргетная медицина). На основе концепции доказательной медицины разработана система стандартов оказания медицинской помощи, в которой индивидуальности больного отводится весьма незначительное место. Тем не менее, именно новейшие достижения молекулярной биологии, реализация проекта «Геном человека» позволяют объединить две, казалось бы, непримиримые философские концепции медицины. Да, болезнь имеет материальный субстрат. В основе происхождения заболеваний лежат весьма конкретные изменения клеток и макромолекул, но именно уникальные особенности каждого человека предопределяют возможность возникновения у него того или иного заболевания, а также в их лечении эффективность того или иного лекарства.

99,9\% генов одинаковы у всех людей. Индивидуальные особенности каждого из нас получили название генетического полиморфизма, определяемого всего лишь $0,1 \%$ генов и проявляющегося в виде полиморфизма единичного нуклеотида, полиморфизма длины рестрикционных фрагментов, коротких тандемных повторов и др. Обусловленная созданием высокоэффективных методов секвенирования нового поколения возможность прочтения индивидуальных геномов вносит индивидуальный подход к лечению и профилактике заболеваний человека и является фундаментальной основой персонифицированной медицины, учитывающей особенности геномов отдельных людей, определяющих склонность человека к развитию у него тех или иных болезней. На основе анализа генетических полиморфизмов возможно создание генетического паспорта, представляющего собой индивидуальную базу ДНК данных, которая отражает уникальные генетические особенности каждого человека, его предрасположенность к 
тем или иным наследственным, мультифакторным и другим заболеваниям. Персонифицированная медицина позволяет оценивать предрасположенность индивидуума к социально значимым заболеваниям, вырабатывать индивидуальный профиль приема лекарственных препаратов, осуществлять раннюю диагностику заболеваний и их профилактику, проводить лечение генами.

В апреле 1953 года в журнале Nature была опубликована статья Джеймса Уотсона и Фрэнсиса Крика «Молекулярная структура нуклеиновых кислот, строение дезоксирибонуклеиновой кислоты» [1]. Именно с этой публикацией связывают возникновение новой биологической науки - молекулярной биологии - науки о молекулярных основах жизни, т.е. механизмах хранения, воспроизведения, передачи и реализации генетической информации, структуре и функциях молекул биополимеров - нуклеиновых кислот и белков [2]. В статье предлагалась трехмерная пространственная модель молекулы ДНК в виде двойной спирали. Из модели вытекал принцип матричных синтезов, т.е. синтезов, при которых информация о структуре синтезируемой молекулы закодирована в строении молекулы-матрицы. На матрице молекулы ДНК синтезируется молекула иРНК, которая, в свою очередь, является матрицей для синтезируемой на рибосомах полипептидной цепи белка. Благодаря этому открытию и предложенному на его основе направлению считывания генетической информации ДНК РНК белок, получившему название центральной догмы молекулярной биологии, последняя получила всеобщее признание. Молекулярная биология использует собственные методы исследования генной инженерии, клонирования клеток и организмов, искусственной экспрессии и нокаута генов. В XX веке молекулярная биология добилась потрясающих результатов, объяснив молекулярные основы важнейших проявлений жизнедеятельности - хранения и передачи генетической информации, иммунитета, клеточного дыхания, апоптоза и др., а также молекулярные механизмы происхождения важнейших болезней человека.

$$
\text { Термин «молекулярная }
$$

болезнь» впервые использовал в 1949 г. Лайнус Поллинг применительно к серповидно-клеточной анемии заболеванию, обусловленному точечной мутацией, сопровождающейся заменой отрицательно заряженной глутаминовой кислоты в 6 положении $\beta$-цепи гемоглобина на гидрофобную аминокислоту валин и приводящей к резкому уменьшению растворимости гемоглобина, выпадению его в осадок, изменению формы эритроцитов и ограничению способности клеток переносить кислород [3].

Отправнойточкойдлявозникновенияновейших направлений медицины, например, генной терапии, терапевтического клонирования, позволяющего получать генно-инженерными методами стволовые клетки и использовать их в качестве лекарств, явилась реализация международного научного проекта «Геном человека» (1989 - 2002 гг.). Проект был направлен на полное секвенирование ДНК Homo sapiens, т.е. установление последовательности из 3,2 $10^{9}$ пар нуклеотидов в молекуле ДНК. Проект был задуман в середине 80-х годов XX века и начал осуществляться с 1990 г. Первоначально ученые полагали, что реализация проекта займет целый век, затем, с учетом небывалого методического прогресса, завершение проекта было запланировано к 2005 г., но фактически основные цели были достигнуты уже к середине 2001 г., и организаторы проекта сообщили о его более чем успешном осуществлении. Реализация проекта предоставила детальную информацию о структуре, организации и функционировании ДНК человека, способствовала разработке новых эффективных технологий в области молекулярной биологии, созданию открытых для свободного доступа международных электронных банков данных генов и белков, привела к возникновению триады новых биологических наук - геномики, протеомики и биоинформатики, имела колоссальное значения для биологии, медицины и международного сообщества в целом и каждого человека в отдельности, открыла новые перспективы к пониманию причин происхождения многих болезней и разработке новых способов их лечения [4].

Сегодня за рубежом термин «молекулярная медицина» переходит из сферы науки в сферу практического здравоохранения. Медицина ближайшего будущего - это персонифицированная медицина, отталкивающаяся от особенностей генома конкретного индивидуума, предрасполагающих к возникновению у него той или иной болезни [5]. Причину возникновения болезни ученые стали видеть в характерных нарушениях генома и протеома (совокупность всех белков клетки и организма в целом), проявляющихся в нарушении структуры того или иного гена и появлении белков с измененными свойствами, получивших название «биологических маркеров» заболевания. Для предупреждения болезни или своевременного лечения необходимо как можно раньше выявить лежащие в ее основе дефекты в геноме и протеоме (биологические маркеры болезни) с помощью молекулярной диагностики, представляющей результат привнесения в клиническую лабораторную диагностику методов ПЦР и макромолекулярного блоттинга. Анализ

Резюме Индивидуальные особенности каждого человека получили название генетического полиморфизма, определяемого всего лишь 0,1\% генов и проявляющегося в виде полиморфизма единичного нуклеотида, полиморфизма длины рестрикционных фрагментов, коротких тандемных повторов и др. Обусловленная созданием высокоэффективных методов секвенирования нового поколения возможность прочтения индивидуальных геномов вносит индивидуальный подход к лечению и профилактике заболеваний человека и является фундаментальной основой персонифицированной медицины, учитывающей особенности геномов отдельных людей, определяющих склонность человека к развитию у него тех или иных болезней. На основе анализа генетических полиморфизмов возможно создание генетического паспорта, представляющего собой индивидуальную базу ДНК данных, которая отражает уникальные генетические особенности каждого человека, его предрасположенность к тем или иным наследственным, мультифакторным и другим заболеваниям. Персонифицированная медицина позволяет оценивать предрасположенность индивидума к социально значимым заболеваниям, вырабатывать индивидуальный профиль приема лекарственных препаратов, осуществлять раннюю диагностику заболеваний и их профилактику, проводить лечение генами. Для создания нового поколения лекарственных препаратов (таргетных препаратов) находят применение методы биоинформатики (компьютерный дизайн лекарств).

Ключевые слова: молекулярная биология, биоинформатика, персонифицированная медицина, традиционная восточная медицина 
биологических маркеров методами молекулярной биологии позволит оценить риск развития болезни, осуществлять мониторинг ее течения, делать выводы в отношении прогноза, а также подбирать лекарственные препараты на основе чувствительности или нечувствительности к ним затронутого гена или белка. Эти гены и белки являются мишенями (targets) для принципиально новых лекарственных препаратов, создаваемых с помощью одного из направлений биоинформатики - компьютерного дизайна лекарств, существенно сокращающего сроки первой стадии разработки лекарства и его стоимость. Ничего не нужно синтезировать. Все, что необходимо, уже есть в электронных базах данных, включающих более 6 миллионов низкомолекулярных соединений.

Следует идентифицировать мишень (ген, белковая молекула) и оценить способность соединения из базы данных взаимодействовать с рецептором. Затем высокоэффективный скрининг, используемый во всем мире в фармакологических целях и позволяющий одновременно анализировать несколько тысяч различных соединений в параллельном режиме. Найденные таким образом базовые структуры уже на следующей стадии путем их химической модификации превращаются в конечное лекарство. Компьютерный дизайн лекарств использует методы вычислительной химии для создания, повышения эффективности и исследования механизма действия лекарственных препаратов. Главная цель - предсказать, будет ли данная молекула связываться с молекулой-мишенью и если да, то насколько прочным будет связывание.

Существуютдве разновидности компьютерного дизайна лекарств - структурный дизайн и дизайн, основанный на свойствах лиганда [6]. При первом отбор «кандидатов» на роль нового лекарства основан на способности узнавать известную трехмерную структуру белка-рецептора (мишени лекарства), устанавливаемую экспериментально методами Rg-структурного анализа, ЯМР-спектроскопии, электронной криомикроскопии. При втором осуществляется поиск «кандидатов», максимально соответствующих характеристикам "фармакофора» - набора характеристик соединения (трехмерная структура, особенности электронного строения и др.), которыми должен обладать кандидат на роль лекарства для оптимального узнавания лекарства рецептором и проявления биологических эффектов.

Компьютерный дизайн может быть использован на любом из этапов создания лекарственного препарата: идентификация мишени для лекарства с использованием виртуального скрининга (structureor ligand-based design), оптимизация сродства и селективности лиганда к мишени (hit-to-lead optimization), оптимизация других фармацевтических свойств препарата с сохранением высокого сродства. Подобный подход лежит в основе таргетной терапии - нового направления в лечении злокачественных опухолей.

Первым лекарственным препаратом, созданным с помощью компьютерного дизайна, является ингибитор карбоангидразы дорзоламид, зарегистрированный в 1995 году. Другим ярким примером эффективности использования компьютерного дизайна явилось создание фирмой Novartis (Швейцария) препарата иматиниб (гливек) - ингибитора тирозинкиназы нового поколения. Препарат зарекомендовал себя как эффективное средство в лечении миелолейкоза и ряда опухолей [7]. Отличиемпрепарата отего предшественников является способность дифференцированно воздействовать на злокачественно трансформированные клетки и не оказывать влияния на нормальные быстро делящиеся клети.

На кафедре химии ФГБОУ ВО Амурская ГМА Минздрава России методы биоинформатики были использованы для разработки нового препарата ингибитора сериновых протеаз на основе соевого ингибитора трипсина [8-10]. Использование методов in silico позволило выявить известную близость первичных структур соевого и панкреатического ингибиторов трипсина (апротинин, действующее начало фармацевтического препарата гордокс, контрикал) и предсказать способность растительного ингибитора оказывать влияние на процессы гемостаза $[8,9]$, что нашло экспериментальное подтверждение в опытах in vitro [10]. В настоящее время на кафедре методы биоинформатики используются для сравнительной характеристики растительных и животных ингибиторов протеаз [11], а также характеристик и TRP-рецепторов [12], моделирования пространственной структуры белков нервной ткани.

Будущая персонифицированная медицина будет основана на выявлении особенностей геномов у отдельных людей, определяющих склонность человека к развитию у него той или иной болезни. Созданы методы секвенирования нового поколения (СНП), позволяющие быстро и относительно дешево расшифоровать геном конкретного индивидуума. Сегодня стоимость секвенирования индивидуального генома составляет около 1000 долларов. Для широкого внедрения метода в практическую медицину стоимость секвенирования необходимо довести до 100 долларов. Принципы технологий СНП базируются на секвенировании ДНК-чипов с использованием

\title{
PERSONIFIED MEDICINE AND BIOINFORMATICS
}

\section{E.A. Borodin}

FSBEI HE Amur State Medical Academy of the Russian Ministry of Health, Blagoveshchensk

\begin{abstract}
The individual characteristics of each person are called genetic polymorphism, determined by only $0.1 \%$ of genes and manifested as a single nucleotide polymorphism, restriction fragment length polymorphism, short tandem repetitions, etc. An individual approach due to the creation of highly efficient sequencing methods of a new generation for the treatment and prevention of human diseases is the fundamental basis of personalized medicine, taking into account the characteristics of the genomes of individuals, determining the propensity of a person to develop a particular disease. Based on the analysis of genetic polymorphisms, it is possible to create a genetic passport, which is an individual DNA database, which reflects the unique genetic characteristics of each person, his predisposition to certain hereditary, multifactor and other diseases. Personalized medicine allows to assess the susceptibility of individual to socially significant diseases, develop an individual profile of medication, carry out early diagnosis of diseases and their prevention, carry out treatment with genes. To create a new generation of drugs (targeted drugs), bioinformatics methods (computer assisted drug design) are used.
\end{abstract}

Key words: molecular biology, bioinformatics, personalized medicine, traditional oriental medicine/ DOI 10.22448/AMJ.2018.4.77-80 
циклических ферментативных реакций. На первом этапе секвенирования создаются библиотеки случайных последовательностей ДНК, которые можно будет сшить с общедоступными адаптерными последовательностями. На втором этапе методом ПЦР создаются ампликоны, которые будут использованы как образцы. На третьем этапе определяются первичные структуры всех фрагментов.

Возможность

секвенирования индивидуальных геномов вносит индивидуальный подход к лечению и профилактике заболеваний человека и является фундаментальной основой персонифицированной медицины, сближая две исторически сложившиеся философскометодологические концепции медицины. На первый взгляд западная методология полностью доминирует в современной медицине и холистический взгляд на природу человека и болезни навечно предан забвению. Однако, как ни парадоксально это звучит, именно новейшие достижения молекулярной биологии, расшифровка генома человека и возможность быстрого прочтения индивидуальных геномов могут объединить две, казалось бы, непримиримые философские концепции медицины. Да, болезнь имеет материальный субстрат. В основе происхождения заболеваний лежат весьма конкретные изменения клеток и макромолекул, но именно уникальные особенности каждого человека предопределяют возможность возникновения у него того или иного заболевания, эффективность того или иного лекарства.

\section{Литература}

1.Watson J., Crick F. (1953). "Molecular structure of nucleic acids; a structure for deoxyribose nucleic acid" . Nature 1953 Vol. 171? No 4356, pp. 737-8Гиппократ. Сочинения. / Пер. В.И.Руднева, комм. В.П.Карпова. Кн. 2.- М.: Медгиз. 1944. 512c.

2.Astbury, W.T. "Molecular Biology or Ultrastructural Biology?" Nature. 1961. Vol. 190, No 4781, p.1124

3.Pauling L.,Itano H., Singer SJ, Wells I. Sickle Cell Anemia, a Molecular Disease". Science, Vol. 110, No. 2865, pp. 543-548.

4.Арчаков А.И. Биоинформатика, геномика и протеомика -науки о жизни XXI столетия // Вопросы медицинской биохимии. 2000. Т. 47. 1. С. 2-9.

5.Щербо С.Н. Персонализированная медицина.

Лабораторные методы. www.ramld.ru/userfiles/file/

Kirov2013/SherboKir.pdf

6.Бородин П.Е., Бородин Е.А. Биоинформатика и компьютерный дизайн лекарств. //Системный анализ в медицине. ДНЦ ФПД СО РАМН (Благовещенск). 2013. с.1113.

7.Ландышев Ю.С., Есенин В.В., Войцеховский В.В. и др. Клинико-эпидемиологические особенности гемобластозов в Амурской области // Дальневосточный медицинский журнал. 1997. №3. С. 31-35.

8.Памирский И.Э., Бородин Е.А., Штарберг М.А. Регуляция протеолиза растительными и животными ингибиторами. - Lambert Academic Publishing, Saarbrucken, Germany, 2012. ISBN 978-3-659-13878-2. 105 c.

9.Eugene A. Borodin, Igor E. Pamirsky, Mikhail A. Shtarberg, Vladimir A. Dorovskikh, Alexander V. Korotkikh, Chie Tarumizu, Kiyoharu Takamatsu and Shigeru Yamamoto Effects of Soy Bean Trypsin Inhibitor on Hemostasis. // Soybean - A Review. (Ed. by Hany A. El-Shemy). In-Tech, Croatia. 2013. p. 495-512. ISBN
978-953-51-0977-8.

10.Памирский И.Э., Штарберг М.А., Белоглазова И.Г., Бородин Е.А. Влияние трипсина и ингибитора трипсина соевых бобов на свертывание крови, фибринолиз, агрегацию тромбоцитов и гемолитическую активность комплемента in vitro // Дальневосточный медицинский журнал. 2008. №1. С. 98-100.

11.Borodin P.E., Borodin E.A. Plant serpins as potential pharmaceuticals for the correction of hemostasis and fibrinolysis disturbances. Bioinformatic study. The 13-th SinoRussia Forum of Biomedical and Pharmaceutical Science. June 16-17, 2016. Harbin, China. P. 24-25.

12.Бородин Е.А., Бородин П.Е. TRP-рецепторы. Биоинформатическая характеристика. //Системный анализ в медицине. ДНЦ ФПД СО РАМН (Благовещенск). 2016. В печати.

13.Бородин П.Е., Карнаух В.Н., Бородин Е.А. Биоинформатическая характеристика белков нервной ткани, вовлеченных в развитие нейро-дегенеративных заболеваний// Сибирское медицинское обозрение. 2017. №6. С. 94-97.

Статья поступила в редакцию 08.11.2018

\section{Координаты для связи}

Бородин Евгений Александрович, д. М. н., профессор, заведующий кафедрой химии ФГБОУ ВО Амурская ГМА Минздрава России. E-mail: borodin54@mail.ru

Почтовый адрес ФГБОУ ВО Амурская ГМА Минздрава России: 675000 г. Благовещенск, ул. Горького, 95. E-mail: science.prorector@AmurSMA.su 